\title{
Inflation Forecasts and Forecaster Herding: Evidence from South African Survey Data
}

October 2014

\begin{abstract}
We use South African survey data to study whether short-term inflation forecasts are unbiased. Depending on how we model a forecaster's information set, we find that forecasts are biased due to forecaster herding. Evidence of forecaster herding is strong when we assume that the information set contains no information on the contemporaneous forecasts of others. When we randomly allocate forecasters into a group of early forecasters who can only observe the past forecasts of others and late forecasters who can observe the contemporaneous forecasters of their predecessors, then evidence of forecaster herding weakens. Further, evidence of forecaster herding is strong and significant in times of high inflation volatility. In time of low inflation volatility, in contrast, forecaster anti-herding seems to dominate.
\end{abstract}

JEL classification: C53, D82, E37

Keywords: Inflation rate; Forecasting; Forecaster Herding

\section{Addresses:}

* Christian Pierdzioch, Helmut-Schmidt-University, Department of Economics, Holstenhofweg 85, P.O.B. 700822, 22008 Hamburg, Germany. Email: c.pierdzioch@hsu-hh.de.

Monique B. Reid. Stellenbosch University, Department of Economics, Private Bag X1, Matieland, South Africa, 7602. Email: mreid@sun.ac.za.

Rangan Gupta, Department of Economics, University of Pretoria, Pretoria, 0002, South Africa. Email: rangan.gupta@up.ac.za.

* Corresponding author. 


\section{Introduction}

A key question for monetary policymakers, and anyone who monitors inflation as an indicator of macroeconomic performance, is whether agents form unbiased inflation expectations. Moreover, inflation expectations are a key element of virtually all modern monetary macroeconomic models. It is, therefore, not surprising that much research has been done to shed light on how agents form their inflation expectations (for detailed reviews of the South African experience, see Naraidoo and Gupta 2010, Kabundi and Schaling 2013). Because it is impossible to observe inflation expectations directly, researchers have extensively studied survey data to analyze the properties of inflation forecasts (for recent examples, see Castelnuovo 2010, Adam and Padula 2011, Del Negro and Eusepi 2011, Fuhrer 2012, to name just a few). A classic topic in this strand of research is whether survey data of agents' inflation forecasts are in line with the rational-expectations hypothesis. In the South African case, a comprehensive investigation of the extent to which inflation expectations are rational is by Ehlers and Steinbach (2007). They assess the characteristics of expectations formation across three different groups of economic agents using the Bureau for Economic Research (BER) inflation expectations survey data and data from the Reuters Inflation Expectations (RIE) Survey. Ehlers and Steinbach (2007) conclude that the expectations of financial analysts and short-term expectations by the trade unions appear unbiased, whereas the expectations of the business representatives and the longer-term expectations of trade unions are biased. However, all the groups were found to use information inefficiently, so none of the groups could be viewed as weakly rational, where the forecasts for the current-quarter horizon from the RIE Survey are an exception. Similarly, Kabundi and Schaling (2013) report, also for the BER data, that inflation expectations are closely tight to the lagged inflation rate. They conclude that inflation expectations are not in line with the rational expectation hypothesis. In a recent study, Kabundi et al. (2014) also report that forecast of price-setters (business representations and unions) are linked to the lagged inflation rate. This, however, is not true for the forecasts of analysts, consistent with cross-sectional heterogeneity of forecasters.

Apart from adaptive learning, Ehlers and Steinbach (2007) do not consider potential behavioral sources of the bias they find in the South African inflation expectations other than an absence of rationality. In this research, we study whether behavioral interactions of forecasters may be a source of bias of inflation expectations. The specific behavioral interaction that we focus on is forecaster herding. Forecaster herding arises when forecasters do not rely only on private information while forming their inflation forecasts but rather manoeuvre their forecasts in the direction of the forecasts of others. Forecaster herding has been extensively studied using theoretical models (see for example, Scharfstein and Stein 1990, Bikhchandani et al. 1992, Ehrbeck and Waldmann 1996, among others), in experimental research (Anderson and Holt 1997, Drehmann et al. 2005), 
and also in empirical research (Chang et al. 2000, Clement and Tse 2005, Bernhardt et al. 2006, among others). ${ }^{1}$ Forecaster herding arises if, for example, weak forecasters and forecasters in an early stage of their career remain close to the consensus forecast (Lamont 2002; see, however, Ashiya and Doi 2001). In contrast, forecaster anti-herding arises if a forecaster's remuneration, in addition to forecast accuracy, depends on the forecaster publicity or on publishing the best forecast at a single point in time (Laster et al. 1999). ${ }^{2}$

We apply a test of forecaster herding recently proposed by Bernhardt et al. (2006) to detect signs of forecaster herding in survey data of inflation forecasts for the South African economy. Recent applications of their test can be found in Frenkel et al. (2013), who study whether IMF and OECD forecasts of the inflation rate and other macroeconomic variables influence private-sector forecasts, and in Pierdzioch and Rülke (2013), who apply the test to study whether inflation targets anchor inflation expectations. The test suggested by Bernhardt et al. (2006) is easy to implement, the economic interpretation of the test results is straightforward, and the test is robust to various forms of misspecification. We apply their test to study short-term inflation forecasts provided by Bloomberg. A specific feature of the data is that Bloomberg publishes forecasts at the time forecasters submit their forecasts. Forecasters, thus, may or may not observe the forecasts of other forecasters when submitting their forecasts. While early forecasters are likely to have rather limited information on the forecasts of other forecasters, late forecasters can take into account a potentially large number of forecasts when submitting a forecast. A direct consequence is that we have to make an assumption as to what forecasters know about the forecasts of others when making their forecasts. When we assume that forecasters mainly rely on past information to estimate the forecasts of others, the test results suggest that forecasters herd. The relevance of past information for the formation of inflation expectations has been documented for different types of forecasters in earlier research by Ehlers and Steinbach (2007), Reid (2012), and Kabundi and Schaling (2013). In the past-information scenario, we detect forecaster herding not only for the full sample of data covering the sample period 2000-2014, but also for various subsample periods including those periods during which the inflation rate fluctuated inside and outside the inflation-targeting band announced by the South African Reserve Bank. Evidence of forecaster herding gets weaker when we assume that forecasters' information set consists of a mix of past and current information on the forecasts of others, but also in this mixed-information scenario our results provide hints that forecasters herd. Furthermore, we find, in line with results reported by Bewley and Fiebig (2002) and Pierdzioch and Rülke (2014), that forecaster herding gets stronger in

\footnotetext{
${ }^{1}$ See Bikhchandani et al. (1998) and Bikchandani and Sharma (2001) for detailed surveys of the vast literature on theoretical and empirical studies on forecaster herding.

${ }^{2}$ A behavioral bias could also arise, for example, if forecasters try to please their employer (Ito 1990), or through media communication Reid and du Plessis, (2011).
} 
times of high inflation volatility. Evidence of forecaster herding in times of high inflation volatility is strong and significant. Uncertainty, thus, seems to trigger forecaster herding. When inflation volatility is low, in contrast, we find evidence that forecasters anti-herd.

We organize the remainder of our research as follows. In order to derive our results, we first lay out the test for forecaster herding in Section 2. We then describe our data in Section 3 and our empirical results in Section 4. We conclude in Section 5.

\section{Empirical Method}

We use a test developed by Bernhardt et al. (2006) to study forecaster herding. To set up their test, we first introduce some notation. We let $\pi_{t}$ denote the inflation rate, and we let $\pi_{t}^{e}$ denote the forecast of the future inflation rate formed in period of time $t$. Moreover, we let $\pi_{t}^{p}$ denote a forecaster's unobservable private forecast. Suppose that a forecaster forms, given an information set available when a forecast is made, a median-unbiased private forecast of inflation. Then the probability that this unbiased private forecast overshoots (undershoots) the future inflation rate should be equal to 0.5 , and this probability should be unrelated to the consensus (average) forecast, $\tilde{\pi}_{t}^{e}$. Hence, regardless of the consensus forecast, the conditional probability, $P$, that a forecast overshoots (undershoots) the future inflation rate should be 0.5 . We have

$$
\begin{aligned}
& P\left(\pi_{t+1}<\pi_{t}^{e} \mid \pi_{t}^{e}>\tilde{\pi}_{t}^{e}, \pi_{t+1} \neq \pi_{t}^{e}\right)=0.5, \\
& P\left(\pi_{t+1}>\pi_{t}^{e} \mid \pi_{t}^{e}<\tilde{\pi}_{t}^{e}, \pi_{t+1} \neq \pi_{t}^{e}\right)=0.5 .
\end{aligned}
$$

Forecaster herding arises if a published forecast is biased towards the consensus forecast. If the biased published forecast exceeds the consensus forecast then we have $\tilde{\pi}_{t}^{e}<\pi_{t}^{e}<\pi_{t}^{p}$. As a result, the probability that the biased published forecast overshoots the future inflation rate should be less than 0.5. Similarly, if the biased published forecast is less than the consensus forecast then we have $\pi_{t}^{p}<\pi_{t}^{e}<\tilde{\pi}_{t}^{e}$, and the probability that the biased published forecast undershoots the future inflation rate also should be less than 0.5. We have

$$
\begin{aligned}
& P\left(\pi_{t+1}<\pi_{t}^{e} \mid \pi_{t}^{e}>\tilde{\pi}_{t}^{e}, \pi_{t+1} \neq \pi_{t}^{e}\right)<0.5, \\
& P\left(\pi_{t+1}>\pi_{t}^{e} \mid \pi_{t}^{e}<\tilde{\pi}_{t}^{e}, \pi_{t+1} \neq \pi_{t}^{e}\right)<0.5 .
\end{aligned}
$$

Finally, forecaster anti-herding implies that forecasters try to differentiate their forecasts from the forecasts of others. In case of forecaster anti-herding, the consensus forecast, thus, "repels" 
forecasts. We have $\tilde{\pi}_{t}^{e}<\pi_{t}^{p}<\pi_{t}^{e}$ and $\pi_{t}^{e}<\pi_{t}^{p}<\tilde{\pi}_{t}^{e}$, such that

$$
\begin{aligned}
& P\left(\pi_{t+1}<\pi_{t}^{e} \mid \pi_{t}^{e}>\tilde{\pi}_{t}^{e}, \pi_{t+1} \neq \pi_{t}^{e}\right)>0.5, \\
& P\left(\pi_{t+1}>\pi_{t}^{e} \mid \pi_{t}^{e}<\tilde{\pi}_{t}^{e}, \pi_{t+1} \neq \pi_{t}^{e}\right)>0.5 .
\end{aligned}
$$

We compute the herding statistic, $S$, proposed by Bernhardt et al. (2006) as the average of the sample estimates of the overshooting and undershooting probabilities. Bernhardt et al. (2006) show that averaging the two probabilities makes the herding statistic robust to various forms of "misspecification". For example, averaging of the two probabilities implies that the statistic does not depend on whether forecasters target the median or the mean of a potentially asymmetric distribution over future inflation rates. Such an asymmetry can easily arise if, for example, the inflation rate approaches the boundaries of its inflation-targeting band.

The herding statistic has an asymptotic normal distribution. The null hypothesis is that forecasters form unbiased forecasts. For unbiased forecasts, we have $S=0.5$, and in case of forecaster herding (anti-herding), we have $S<0.5(S>0.5)$. The variance of the herding statistic reaches a maximum under the null hypothesis of unbiased forecasts, implying that the herding statistic is conservative in the sense that, under the null hypothesis, a researcher maximizes the difficulty to reject the null hypothesis of unbiased forecasts.

\section{The Data}

We study monthly survey data of inflation forecasts for South Africa. The data were provided by Bloomberg. Forecasts are for the year-on-year CPI inflation rate and the year-on-year CPIX inflation rate, where the latter excludes mortgage costs. Forecasts are short-term forecasts. For example, forecasters form forecast in May of the inflation rate released in June. The sample period is 2000/05-2014/06 for the CPI data, and 2000/05-2008/12 for the CPIX data. In total, we have available forecasts from 82 forecasters in case of CPI inflation, and for 63 forecasters in case of CPIX inflation. Not all forecasters participated in all surveys. Hence, we study an unbalanced panel of data.

Figure 1 plots summary statistics of the data, where the upper row shows the CPI inflation data and the lower row the CPIX inflation data. The summary statistics highlight four main features of the data. First, we observe that forecasts closely track actual inflation. This is what we expected given that forecasts are short-term forecasts. Second, despite the close link between actual inflation 
and forecasts of inflation, we also observe some scattering of forecasts. The scattering of forecasts is a characteristic feature of both forecasts of CPI inflation and forecasts of CPIX inflation. We interpret the scattering of forecasts as evidence of forecaster heterogeneity (see also the analysis of inflation forecasts by Pierdzioch and Rülke 2013). Moreover, the scattering of forecasts can be observed irrespective of whether the actual inflation rate settled inside or outside the $3 \%-6 \%$ inflation-targeting band, suggesting that whatever is causing the scattering is not linked to whether or not inflation is under control (within the target). Third, the population of forecasters is also heterogeneous with respect to the frequency of participation in the survey. The histograms shown in Figure 1 reveal that few forecasters participated more or less regularly in the survey, while many other forecasters participated only occasionally. The median of the number of forecasts per forecasters is 17 (16) for the CPI (CPIX) forecasts. Fourth, participation in the survey increased over time, as can be observed by eyeballing the barplots shown in Figure 1.

- Please include Figure 1 about here. -

Every survey starts off with Bloomberg sending questionnaires to the forecasters. The forecasters then submit forecasts, but typically do not do so simultaneously. Hence, some forecasters are early forecasters while others are late forecasters. Bloomberg collects the various incoming forecasts and publishes them as it receives them. The immediate publication of forecasts implies that late forecasters know the forecasts submitted by early forecasters even before the day on which Bloomberg simultaneously publishes all forecasts (call this the observation date). Bloomberg publishes all forecasts just before the day on which official real-time data on inflation are released (the so called release date).

While we have available data on all forecasts that Bloomberg published on an observation date, we do not have information on which forecasts Bloomberg published first and which forecasts it published later on. Because we cannot discriminate between early and late forecasts, we cannot track exactly a forecaster's information set. This imperfect tracking of a forecaster's information set is important because the herding statistic requires computation of a consensus forecast. In principle, a late forecaster can compute an approximate consensus forecast if several early forecasters already have published their forecasts. Earlier forecasters, in contrast, may find it difficult to compute even an approximate consensus forecast simply because Bloomberg, at the time when an early forecaster forms his or her forecast, has published only a few forecasts. All we know is that both early and late forecasters learn about the full set of forecasts submitted by others only on the observation date. Both types of forecasters, thus, can compute an exact consensus forecast, and the position of forecasts relative to the consensus forecast, only on the observation date. 
In our empirical analysis, we illustrate the implications of different assumptions regarding a forecaster's information set by using the contemporaneous consensus forecast and the lagged consensus forecast to set up the herding statistic. While the contemporaneous consensus forecast is not in a forecaster's information set, all forecasters easily can observe the lagged consensus forecast. In terms of the notation introduced in Section 2, we replace the contemporaneous period- $t$ consensus forecast, $\tilde{\pi}_{t}^{e}$, with the period- $t-1$ consensus forecast, $\tilde{\pi}_{t-1}^{e}$ (see also Pierdzioch and Rülke 2013). Using the lagged consensus forecast to estimate the herding statistic also is justified by results reported by Ehlers and Steinbach (2007) that expectation formation features an adaptive component. Moreover, Kabundi and Schaling (2013) find for the BER inflation expectations survey data that the lagged inflation rate exerts a strong influence on forecasters' inflation expectations. Kabundi et al. (2014) confirm this result insofar as they show that the inflation expectations' dependence on the lagged inflation rate is mainly concentrated among price setters (business representatives and unions) but not among analysts. Hence, it appears that forecasters are heterogenous with regard to the information they use to form their expectations. Because Figure 1 shows that forecaster heterogeneity also is a feature of our data, we use, in addition to approximating forecasters' information set by means of the lagged consensus forecast, a simulation experiment to mimic the way Bloomberg collects and publishes the forecasts.

\section{Empirical Analysis}

Table 1 depicts the point estimate of the herding statistic, its standard error, the various elements that we need to construct the herding statistic, and the number of observations available. To explain the table, we consider the CPI data for the full sample. Using the lagged consensus forecast to set up the herding statistic, we have 1,426 observations for which the inflation forecast exceeds the lagged consensus forecast, and we have 619 observations for which the inflation forecast exceeds both the lagged consensus forecast and the actual inflation rate. Hence, we compute the overshooting probability as $619 / 1,426=0.4341$. Similarly, we have 1,234 observations for which the inflation forecast falls short of the lagged consensus forecast, and 481 forecasts that fall short of both the lagged consensus forecast and the actual inflation rate. The undershooting probability is, thus, given by $481 / 1,234=0.3898$. Summing up the overshooting and undershooting probabilities and computing their arithmetic average gives $S=\frac{1}{2} \times(0.4341+0.3898)=0.4119$, the point estimate of the $S$-statistic. The point estimate of the herding statistic, $S<0.5$, is smaller than its benchmark value indicating that forecasters herd.

In sharp contrast, the herding statistic is larger than in the benchmark case of unbiased forecasts when we use the contemporaneous consensus forecast (CCF). A herding statistic that is larger 
than its benchmark value, $S=0.5$, indicates forecaster anti-herding. The CCF-herding statistic, however, is difficult to interpret because the contemporaneous consensus forecast is not in a forecaster's information set. A forecaster may compute an approximate estimate of the contemporaneous consensus forecast from early forecasts or from other sources (for example, some forecasters may publish their forecasts in the media) but the precise value of the contemporaneous consensus forecast is only available on the observation date. A forecaster, therefore, also does not know whether his or her forecast exceeds or falls short of the contemporaneous consensus forecast. Instead, a forecaster may use, for example, the results of private research to update his or her assessment of the conditioning information and the resulting updating should shift the conditional probabilities such that even in case of unbiased forecasts the herding statistic is larger than in the past-information scenario that is exclusively based on the lagged consensus forecast. In the end, the CCF-herding statistic signals forecaster anti-herding, $S>0.5$, under the null hypothesis and, thus, overstates the case for forecaster anti-herding. Still, the marked difference between the CCF-herding statistic and the herding statistic based on the lagged consensus forecast highlights the importance of how we model the flow of information across forecasters.

- Please include Table 1 about here. -

When we use the lagged consensus forecast, the herding statistic is smaller than its benchmark value not only when we consider the full sample of data, but also for various special cases. The first special case that we consider is a sample split in 2008/12 because the South African Reserve Bank then switched from targeting CPIX inflation to targeting CPI inflation. The results summarized in Table 1 show that this sample split does not alter our main result that the herding statistic is smaller than its benchmark value. The next special case that we consider captures the result highlighted in Figure 1 that some forecasters very often participated in the survey, while other forecasters only participated occasionally. Accordingly, we compute the herding statistic excluding those forecasters from the sample who contributed less than the median number of forecasts to the survey. Again, the herding statistic is smaller than its benchmark value. As yet another special case, we split the sample using only data for those periods of time when the inflation rate settled inside (outside) its inflation-targeting band. The results reported in Table 1 witness that again the herding statistic is smaller than its benchmark value. ${ }^{3}$

\footnotetext{
${ }^{3}$ Naraidoo and Gupta (2010) find that an unofficial inflation-targeting band of $4.5 \%-6.9 \%$ provides a more plausible description of the actual monetary policy of the South African Reserve Bank than the official $3 \%-6 \%$ band. Accordingly, we also computed the herding statistic for such an unofficial inflation-targeting band. Inside (outside) this band, we obtained a herding statistic of $0.4142^{* * *}\left(0.4117^{* * *}\right)$ for the CPI-based inflation rate, with the corresponding values being $0.512\left(0.3473^{* * *}\right)$ for the CPIX-based inflation rate, where the asterisks indicate significance as in Table 1.
} 
- Please include Figure 2 about here. -

As a further exercise, we compute rolling-window estimates of the herding statistic, again using the lagged consensus forecast to approximate a forecaster's information set. Figure 2 summarizes the results. As expected, the time-path of the herding statistic gets smoother as we increase the length of the rolling-estimation window from two years to four years and then to six years. For the two-year rolling-estimation window, we observe that the herding statistic temporarily exceeds its benchmark value during a short episode at around 2005 and in 2007 in case of the CPI inflation rate, and around 2004/2005 in case of the CPIX inflation rate. These temporary increases in the herding statistic fit well with prior expectations based on Figure 1. The period 2004/5-2007 is the most stable period that South Africa have had experienced under inflation targeting in the sense that it was the longest period of time during which the inflation rate fluctuated within the inflation-targeting band, and it was a period of relatively low inflation volatility (see also Figure 4 below). Hence, while the results depicted in Table 1 suggest that forecaster herding dominated irrespective of whether the inflation rate fluctuated within the inflation-targeting band, the rollingwindow estimates provide signs that forecasters did not herd or even switched to an anti-herding strategy in times of a relatively stable inflation rate. We shall investigate switching between herding and anti-herding more formally below (see Table 4).

- Please include Table 2 about here. -

Perhaps simply assuming that forecasters use the lagged consensus forecast is a somewhat static view of the forecasting process. For this reason, we also estimate another version of the herding statistic assuming that forecasters forecast not only the inflation rate but also the consensus forecast. To this end, we assume that forecasters estimate, in every period of time, an autoregressive (AR) model of order one for the consensus forecast: $\tilde{\pi}_{t}^{e}=\beta_{0}+\beta_{1} \tilde{\pi}_{t-1}^{e}+\epsilon_{t}$, where $\beta_{0}$ and $\beta_{1}$ are the coefficients to be estimated and $\epsilon_{t}$ is a stochastic disturbance term. We further assume that forecasters use a rolling-estimation window to estimate the AR model for the consensus forecast, and use the one-period-ahead forecast from this model to forecast the consensus forecast. Table 2 summarizes the results that we obtain when we calculated the herding statistic using the one-period-ahead forecast as a proxy for the contemporaneous consensus forecast. Because we lose several years of data to initialize the estimation of the AR model for the consensus forecast, we focus on the full sample of data. Using alternative rolling-estimation-windows of $4-6$ years lengths, we find that the herding statistic is significantly smaller than its benchmark value in all cases. 
We run a simulation experiment to mimic the way Bloomberg collects and publishes the forecasts. The idea motivating the simulation experiment is that we can approximate a forecaster's information set by subdividing, in every period of time, the group of forecasters who deliver forecasts into a group of early and a group of late forecasters. Hence, if we have available in period of time $t$ a total of $n$ forecasts, we line up forecasters and randomly declared $x$ forecasters as early forecasters and the remaining $n-x$ forecasters as late forecasters, where $1<x<n$ is a random number. We then assume that early forecasters use the lagged consensus forecast, $\tilde{\pi}_{t-1}^{e}$, when deciding on their forecasts. Late forecasters, in contrast, have available information on the forecasts of early forecasters. As a result, we assume that late forecasters use the average of the early forecasts to compute a contemporaneous consensus forecast. We repeat this random formation of early and late forecasters in every periods of time such that a forecaster who is a late forecaster in period of time $t$ may by an early forecaster in period of time $t+1$. We then run our simulation experiment 10, 000 times and compute the mean and the variance of the resulting sampling distribution. We use the mean of the sampling distribution as a point estimate of the $S$ statistic, and we use its variance to compute the boundaries of the $90 \%$ and the $95 \%$ confidence intervals of the $S$ statistic.

- Please include Figure 3 and Table 3 about here. -

Figure 3 shows the simulated sampling distributions that we obtained for the full sample of data. The sampling distributions closely match a normal distribution, as one would have expected given the asymptotic properties of the herding statistic. For the CPI data, the sampled mean value of the herding statistic (full sample of data) is $S=0.4887$ and the $90 \%$ and $95 \%$ confidence intervals are $(0.4680,0.5094)$ and $(0.4611,0.5133)$. For the CPIX, we have $S=0.4746$ and the $90 \%$ and $95 \%$ confidence intervals are $(0.4471,0.5022)$ and $(0.4419,0.5074)$. As expected given the CCFherding statistic reported in Table 1, the simulated herding statistic is larger and, thus, closer to its benchmark value than when we use the lagged consensus forecast as a proxy for a forecaster's information set. Still, both point estimates are smaller than the benchmark value that applies in the case of unbiased forecasts. Moreover, both herding statistics are significant at the $10 \%$ level (neglecting the third post decimal positions).

Table 3 summarizes the simulation results for various subsample periods. As compared to the results given in Tables 1 and 2, the herding statistic is much less significant. As already mentioned, however, the upper boundaries of the confidence intervals scratch the benchmark value of the herding statistic if we study the full sample of data for both the CPI and the CPIX inflation rates, and for the CPI inflation rate during the subsample period 2000/01-2008/12. Moreover, the herding statistic is significant when we study the period of time during which the CPIX inflation rate settled outside of the inflation-targeting band. 
Finally, we analyze forecaster herding during months of low and high inflation volatility. In earlier research, Bewley and Fiebig (2002) find that interest-rate forecasters tend to herd in times of high volatility. Similarly, Pierdzioch and Rülke (2014) find that higher interest-rate volatility tends to weaken incentives to anti-herd. In order to inspect the potential nexus between forecaster herding and inflation volatility, we defined a low-volatility regime and a high-volatility regime. In a lowvolatility regime, the absolute change in the inflation rate from the previous month is smaller or equal than its unconditional full sample mean. In a high-volatility regime, in turn, the absolute change in the inflation rate from the previous month is larger than its unconditional full sample mean. Figure 4 shows inflation volatility for both the CPI and the CPIX inflation rate along with the respective unconditional means. Inflation volatility calculated based on the CPI data peaked in 2003 and then again in 2008. Inflation volatility calculated based on the CPIX data exhibits a pronounced peak in 2003 and increased again at around 2008. Comparing the periods of high inflation volatility with the path of the inflation rate shown in Figure 1, it becomes evident that periods of high inflation rates were also periods of high inflation volatility, in line with the Friedman (1977) hypothesis.

- Please include Figure 4 and Table 4 about here. -

Table 4 summarizes the results for the herding statistic. When we use the lagged consensus forecast to approximate a forecaster's information set, we observe in the low-volatility regime that the herding statistic is either close to its benchmark value (CPI inflation rate) or that it significantly exceeds its benchmark value (CPIX inflation rate), indicating forecaster anti-herding. In the high-volatility regime, in contrast, the herding statistic is significantly smaller than its benchmark value. In fact, the herding statistic assumes values of 0.26 and 0.23 and, thus, is much smaller than all herding statistics reported in Tables $1-3 .{ }^{4}$ It, therefore, is not surprising that the herding statistic also is significantly smaller than its benchmark value when we use our simulation experiment to model a mixed-information scenario in which the population of forecasters consists of early and late forecasters. We conclude that forecaster herding dominates in times of high inflation volatility. In times of low inflation volatility, in contrast, the results of the simulation experiments yield significant evidence of forecaster anti-herding.

\footnotetext{
${ }^{4}$ Defining the threshold that separates the low-volatility regime from the high-volatility regime in terms of the unconditional mean of inflation volatility is somewhat arbitrary. Using the sum of the unconditional mean plus one unconditional standard deviation of inflation volatility as an alternative threshold, the herding statistic for the the CPI inflation rate assumes the values $0.4281^{* * *}\left(0.2609^{* * *}\right)$ in the low-volatility (high-volatility) regime. For the CPIX inflation rate, the herding statistic assumes the values $0.4254^{* * *}\left(0.1719^{* * *}\right)$ in the low-volatility (highvolatility) regime, where asterisks indicate significance (see also Table 4). For the alternative threshold, however, the number of observations in the high-volatility regime gets small.
} 


\section{Concluding Remarks}

Summing up, evidence of forecaster herding depends on the way we model the flow of information across forecasters and on inflation volatility. If we use the lagged consensus forecast, we find that forecaster herding is a characteristic feature of South African short-term inflation forecasts. Given that earlier researchers have found that the lagged inflation rate plays a non-negligible role for the formation of inflation expectations, our assumption in the past-information scenario that the lagged consensus forecast proxies a forecaster's information set seems not implausible. Forecaster herding implies that forecasters do not publish unbiased results and, thus, may help to explain biases that earlier researchers have documented. As compared to the results for the pastinformation scenario, evidence of forecaster herding is weaker in the mixed-information scenario where we subdivide the group of forecasters into a group of early and a group of late forecasters. The herding statistic is still smaller than its benchmark value in the mixed-information scenario but it is no longer strongly significant. Still, the herding statistic remains weakly significant for the full sample of data and for some subsample periods. Finally, forecaster herding seems to get stronger in times of high inflation volatility, irrespective of whether we consider the pastinformation or the mixed-information scenario. In times of low inflation volatility, in contrast, it seems that forecasters anti-herd. Hence, the strength of the case for forecaster herding depends on the extent to which forecasters take into account past versus contemporaneous information when forming their inflation expectations and on uncertainty measured in terms of inflation volatility.

It is worth mentioning that even if forecasts are biased they still may be useful for forecasting short-term dynamics of inflation. Forecaster herding is a cross-sectional feature of forecasts, while their informational content with respect to the short-term dynamics of inflation is a concept that relates, for example, to the directional accuracy of forecasts over time. It is also worth mentioning that our empirical analysis is silent with regard to the credibility of the South African inflation-targeting band. Testing the credibility of an inflation-targeting band would require a test of whether forecasters chase some form of inflation target when forming their forecasts (see for example, Pierdzioch and Rülke 2013). Our results only provide signs that forecasters tend to lean against the (lagged) consensus forecast when forming their forecasts, and that this tendency grows stronger in times of high inflation volatility. However, in terms of economic policy, a positive link between forecaster herding and high inflation volatility suggests that establishing a credible inflation-targeting regime not only has the potential to lead to low inflation rates and to anchor inflation expectations. Rather, an inflation-targeting regime also may bring about a change in the process of expectation formation. While our results suggest that such a process change may reflect that lower inflation rates lead to less forecaster herding, it is not necessarily true that lower inflation rates also imply that forecasts are less biased. Rather than leading to less biased forecasts, 
low inflation rates may as well lead to forecaster anti-herding. An interesting avenue for future research is to explore, in a single country across monetary-policy regimes or in a cross-section of countries, the link between inflation rates, inflation volatility, and forecaster (anti-)herding in more detail. If high inflation rates lead to high inflation volatility and, as our results suggest, high inflation volatility strengthens forecasters' incentives to herd, then such research also would recover an hitherto neglected new implication of the Friedman (1977) hypothesis.

\section{References}

Ashiya M., T. Doi. (2001). Herd behavior of Japanese Economists. Journal of Economic Behavior and Organization 46: 343-346.

Adam K, M. Padula (2011). Inflation Dynamics and Subjective Expectations in the United States. Economic Inquiry 49: 13-25.

Anderson, L., C. Holt (1997). Information Cascades in the Laboratory, American Economic Review 87: 847-862.

Bernhardt D., Campello M., E. Kutsoati (2006). Who Herds? Journal of Financial Economics 80: $657-675$.

Bewley, R., D. G. Fiebig (2002). On the Herding Instinct of Interest Rate Forecasters. Empirical Economics 27: 403-425.

Bikchandani, S., S. Sharma (2001). Herd Behavior in Financial Markets. IMF Staff Papers 47: $279-310$.

Bikhchandani, S., D. Hirshleifer, I. Welch (1992). A Theory of Fads, Fashion, Custom, and Cultural Change as Informational Cascades. Journal of Political Economy 100: 992-1026.

Bikhchandani, S., D. Hirshleifer, I. Welch (1998). Learning from the Behavior of Others: Conformity, Fads, and Informational Cascades, Journal of Economic Perspectives 12: 151-170.

Castelnuovo, E. (2010). Tracking U.S. Inflation Expectations With Domestic and Global Indicators. Journal of International Money and Finance 29: 1340-1356.

Chang, E.C., Cheng, J.W., A. Khorana (2000). An examination of herd behavior in equity markets: An international perspective. Journal of Banking and Finance 24: 1651-1679.

Clement, M.B., S.Y. Tse (2005). Financial Analyst Characteristics and Herding Behavior in Forecasting. Journal of Finance 60: 307-341.

Del Negro, M., S. Eusepi (2011). Fitting Observed Inflation Expectations, Journal of Economic Dynamics and Control 35: 2105-2127.

Drehmann, M., J. Oechssler, A. Roider (2005). Herding and Contrarian Behavior in Financial Markets: An Internet Experiment. American Economic Review 95: 1403-1426. 
Ehlers, N., M. R. Steinbach (2007). The formation of inflation expectations in South Africa. Working Paper WP/07/06, South African Reserve Bank.

Ehrbeck, T., R. Waldmann (1996). Why are Professional Forecasters Biased? Agency versus Behavioral Explanations. Quarterly Journal of Economics 111: 21-40.

Frenkel, M., Rülke, J.C., L. Zimmermann (2013). Do Private Sector Forecasters Chase After IMF or OECD Forecasts? Journal of Macroeconomics 37: 217-229.

Friedman, M. (1977). Nobel Lecture: Inflation and Unemployment. Journal of Political Economy 85: $451-472$.

Fuhrer J. (2012). The Role of Expectations in Inflation Dynamics. International Journal of Central Banking 81: 137-165.

Ito T. (1990). Foreign Exchange Rate Expectations: Micro Survey Data. American Economic Review 80: 434-449.

Kabundi, A., E. Schaling (2013). Inflation and Inflation Expectations in South Africa: An Attempt at Explanation. South African Journal of Economics 81: 346-355.

Kabundi, A., Schaling, E., M. Some (2014). Monetary Policy and Heterogeneous Inflation Expectations in South Africa. Working Paper No. 422, Economic Research Southern Africa.

Lamont, O.A. (2002). Macroeconomic Forecasts and Microeconomic Forecasters. Journal of Economic Behavior and Organization 48: 265-280.

Laster D., Bennett, P., S. Geoum (1999). Rational Bias in Macroeconomic Forecasts. Quarterly Journal of Economics 114: 293-318.

Naraidoo, R., R. Gupta (2010). Modelling Monetary Policy in South Africa: Focus on Inflation Targeting Era Using a Simple Learning Rule. International Business and Economics Research Journal 9: 89-98.

Pierdzioch, C., J.C. Rülke (2013). Do Inflation Targets Anchor Inflation Expectations? Economic Modelling 35: 214-223.

Pierdzioch, C., J.C. Rülke (2014). Do Interest-Rate Forecasters Herd? International Evidence. Applied Economics Letters 21: 93-98.

R Development Core Team (2014). R: A Language and Environment for Statistical Computing. Internet address: http://www.R-project.org.

Reid, M.B., S. du Plessis (2011). Talking to the Inattentive Public: How the Media Translates the Reserve Bank's Communications. Working Paper No. 254, Economic Research Southern Africa.

Reid, M.B. (2012). Inflation Expectations of the Inattentive General Public. Working Paper No. 278, Economic Research Southern Africa.

Scharfstein, D.S., J.C. Stein (1990). Herd Behavior and Investment, American Economic Review 80: $465-479$. 


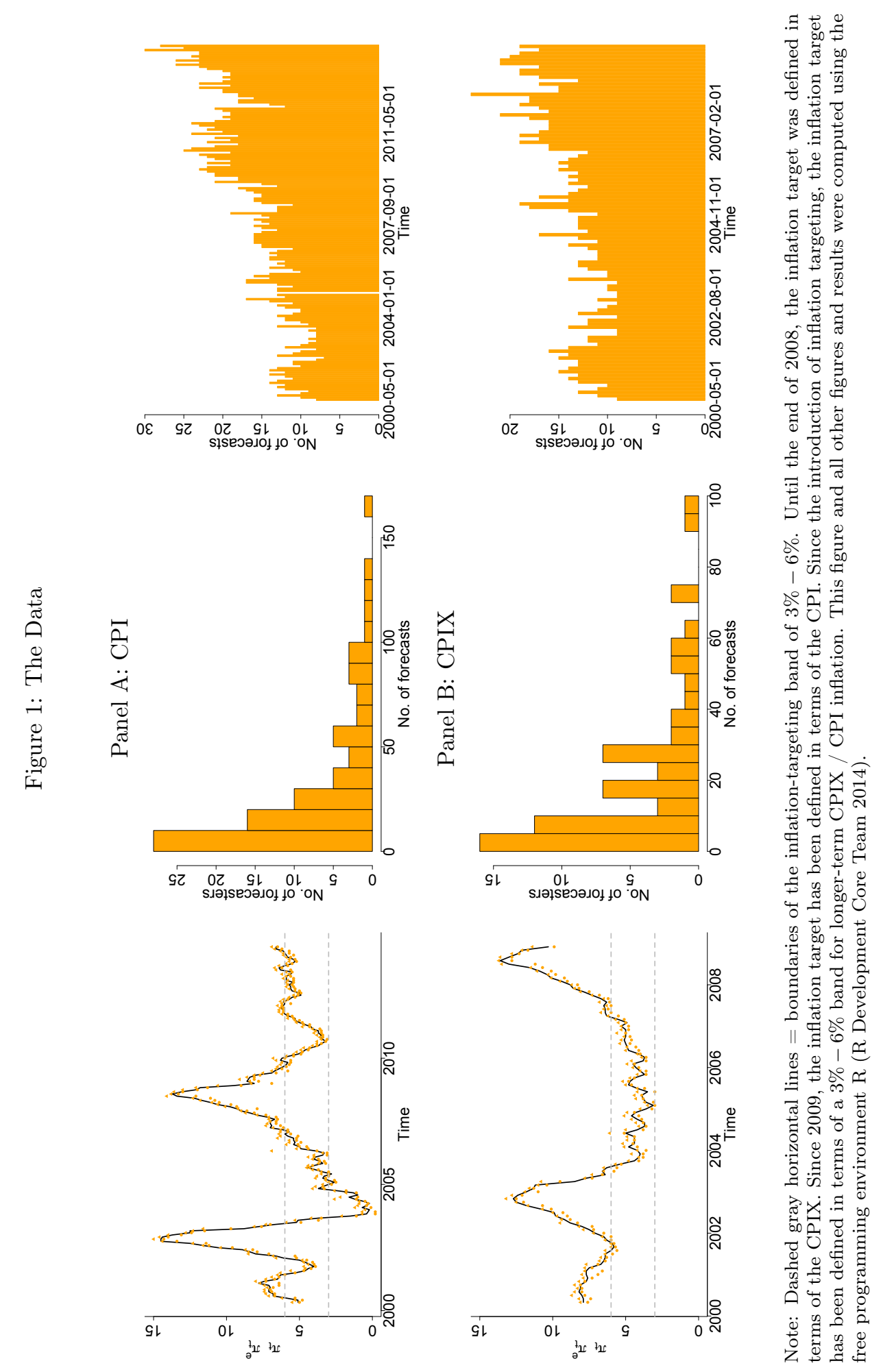




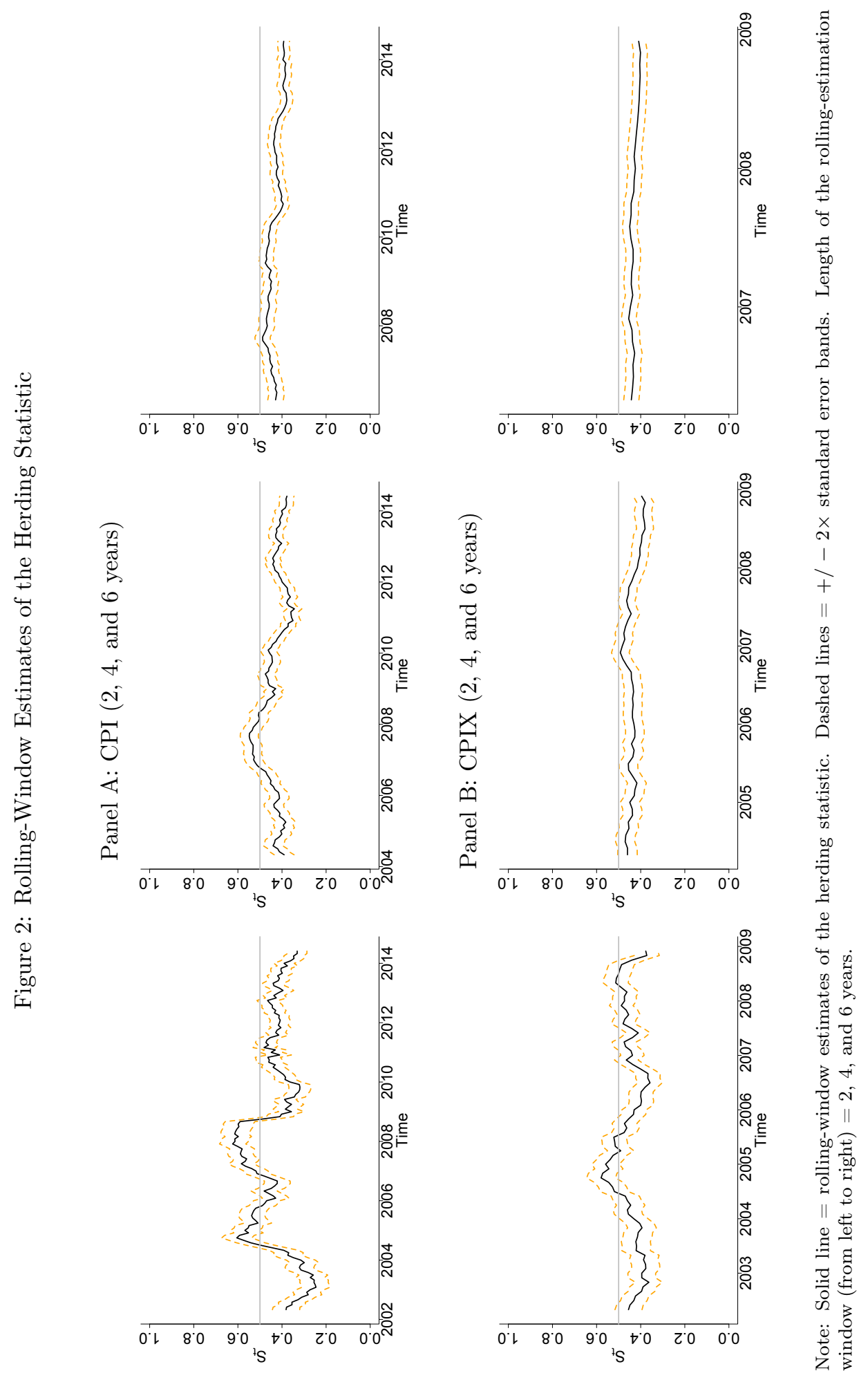




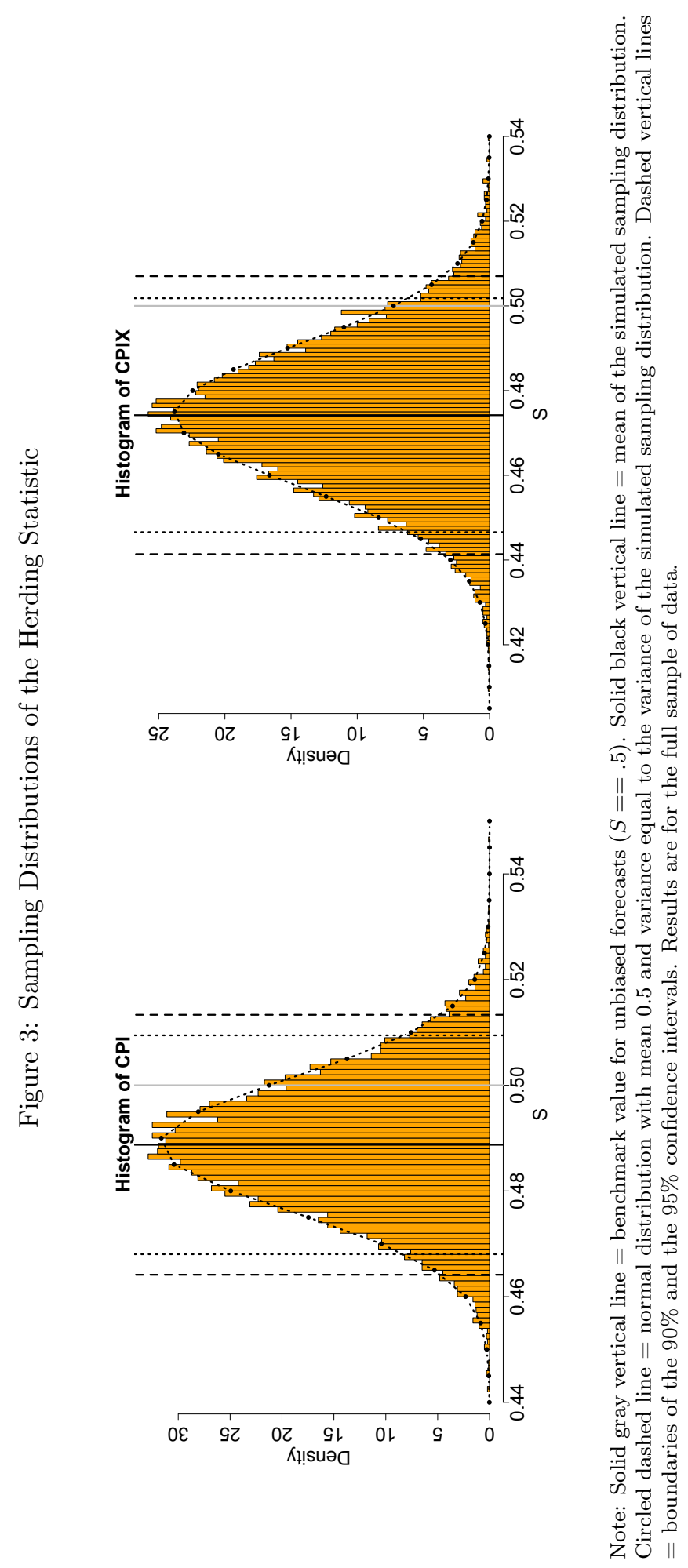




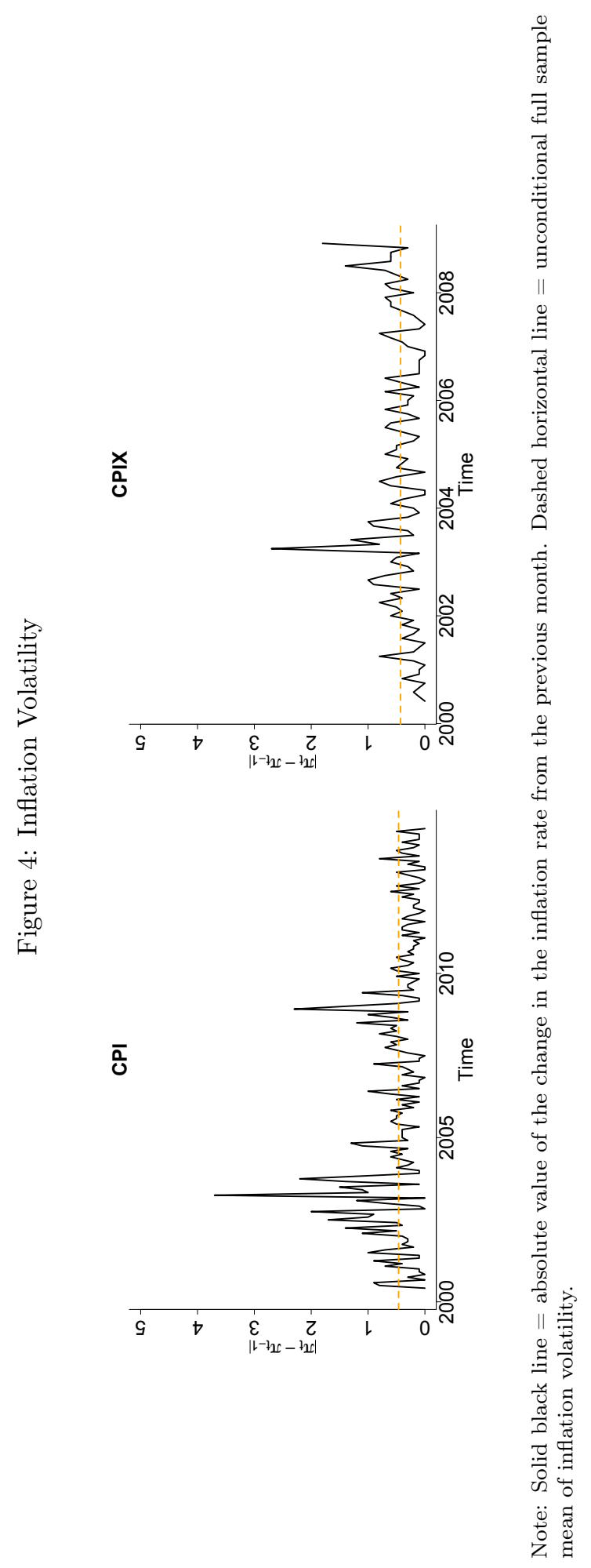




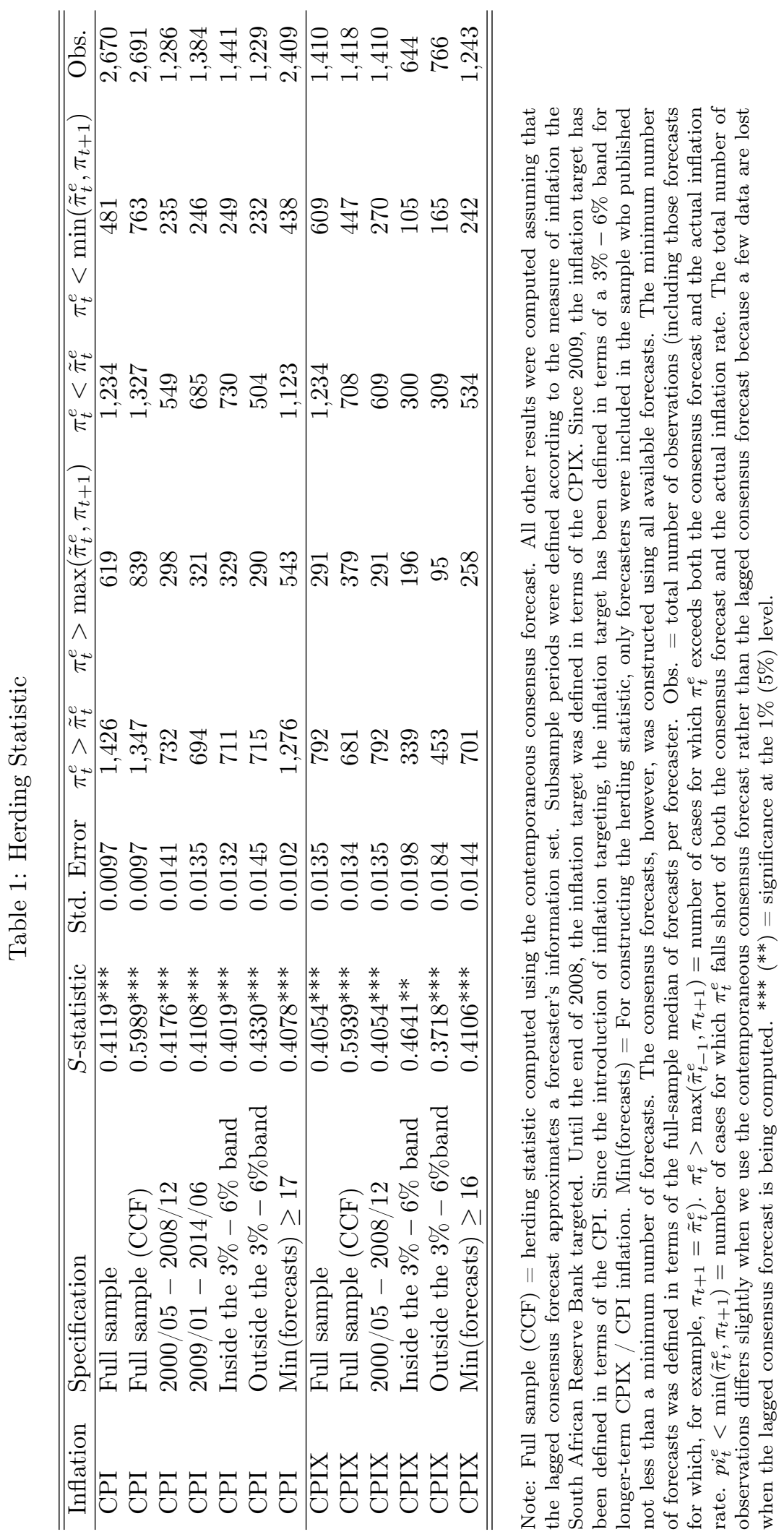


Table 2: Forecasting the Consensus Forecast

\begin{tabular}{ccc}
\hline \hline$S$-statistic & CPI & CPIX \\
\hline 48 months & $0.4121^{* * *}$ & $0.3836^{* * *}$ \\
60 months & $0.4063^{* * *}$ & $0.3726^{* * *}$ \\
72 months & $0.4044^{* * *}$ & $0.4173^{* * *}$ \\
\hline \hline
\end{tabular}

Note: Herding statistic when forecasters forecast the consensus forecast by mean of an autoregressive (AR) model of order one. The AR model is estimated using a rolling-estimation window of length 48,60 , and 72 months. Results are for the full sample of data. ${ }^{* *}=$ significance at the $1 \%$ level.

Table 3: Simulation Results

\begin{tabular}{llccc}
\hline \hline Inflation & Specification & $S$-statistic & $90 \%$ CI & $95 \%$ CI \\
\hline CPI & Full sample & $0.4887^{*}$ & $(0.4680,0.5094)$ & $(0.4641,0.5133)$ \\
CPI & $2000 / 05-2008 / 12$ & 0.4996 & $(0.4733,0.5260)$ & $(0.4684,0.5306)$ \\
CPI & $2009 / 01-2014 / 06$ & 0.4824 & $(0.4506,0.5143)$ & $(0.4446,0.5203)$ \\
CPI & Inside the $3 \%-6 \%$ band & 0.4909 & $(0.4621,0.5197)$ & $(0.4566,0.5251)$ \\
CPI & Outside the $3 \%-6 \%$ band & 0.4947 & $(0.4649,0.5246)$ & $(0.4593,0.5302)$ \\
\hline CPIX & Full sample & $0.4746^{* *}$ & $(0.4471,0.5022)$ & $(0.4419,0.5074)$ \\
CPIX & $2000 / 05-2008 / 12$ & $0.4743^{* *}$ & $(0.4464,0.5022)$ & $(0.4412,0.5075)$ \\
CPIX & Inside the $3 \%-6 \%$ band & 0.5053 & $(0.4688,0.5418)$ & $(0.4620,0.5487)$ \\
CPIX & Outside the $3 \%-6 \%$ band & $0.4634^{* *}$ & $(0.4268,0.4999)$ & $(0.4200,0.5067)$ \\
\hline \hline
\end{tabular}

Note: The simulation experiments were run as described in Section 4. Accordingly, the group of forecasters was subdivided randomly in every period of time into a group of early forecasters and a group of late forecasters. Early forecasters use the lagged consensus forecast. Late forecasters use the contemporaneous consensus forecast of the early forecasters. CI $=$ confidence band. Number of simulation runs $=10,000$. Subsample periods were defined according to the measure of inflation the South African Reserve Bank targeted. Until the end of 2008, the inflation target was defined in terms of the CPIX. Since 2009, the inflation target has been defined in terms of the CPI. Since the introduction of inflation targeting, the inflation target has been defined in terms of a $3 \%-6 \%$ band for longer-term CPIX / CPI inflation. ${ }^{* *}(*)=$ significance at the $5 \%(10 \%)$ level (neglecting the third post decimal positions). 


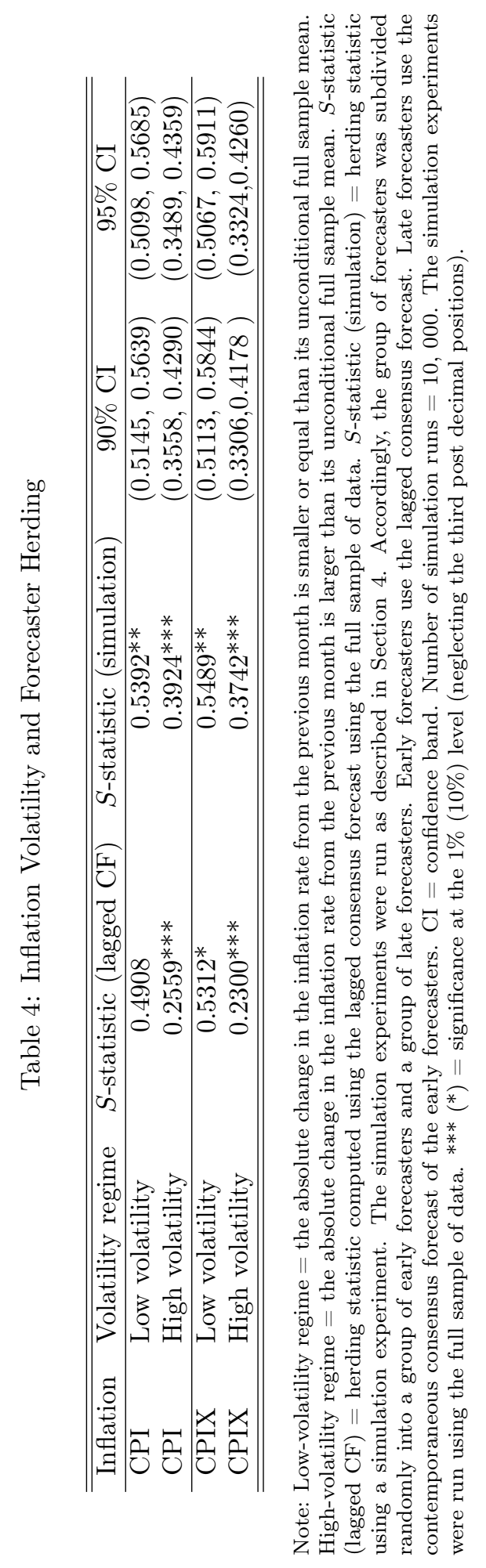

